\title{
A New Look at Farmers' Markets: Consumer Knowledge and Loyalty
}

\author{
Zhifeng Gao ${ }^{1}$ \\ Food and Resource Economics Department, University of Florida, Gainesville, \\ FL 32611 \\ Marilyn Swisher \\ Family, Youth and Community Sciences Department, University of Florida, \\ Gainesville, FL 32611
}

Xin Zhao
Horticultural Sciences Department, University of Florida, Gainesville, FL
32611

Additional index words. farmers' market, locally grown, organic, fresh produce

\begin{abstract}
Farmers' markets (FMs) are perceived as ideal places for consumers to purchase fresh, local, and organic produce; for small- and midsized farmers, to gain reliable income; and for stimulating the local economy. However, with the organic and local food movements gaining momentum, it may be hard to keep up with all the expectations for FMs. This is because the rapid growth of FMs may provide more opportunities for vendors who use misleading labels and statements to attract consumers. The objective of this study was to determine consumer perception and knowledge of FMs as well as consumer persistence of shopping at FMs after finding out that the FM products do not meet their expectations. The results indicated that FM shopping atmosphere, environmental consciousness, product freshness, and local production were the main reasons for consumers shopping at FMs. This study showed that the majority of consumers had limited knowledge of individual FM vendors; most consumers would continue to shop at FMs even after purchasing products that did not meet their expectations; and consumers who believed buying locally at FMs was important were more likely to stop shopping if dishonest vendor practices were revealed than were consumers who used FMs mainly as places for socializing and meeting friends.
\end{abstract}

The number of FMs in the United States increased dramatically from 1775 in 1994 to 7751 in 2011 with the U.S. Department of Agriculture (USDA) providing support such as funding to promote the establishment of more FMs (AMS/USDA, 2011a, 2011b). The increased number of FMs and USDA funding support reflect society's demand for the services that FMs provide (Alonso and O'Neill, 2010). FMs provide an opportunity for growers, particularly small- and midsized growers, to sell their products for a retail price, thereby serving as another source of farm income. They provide consumers with alternative ways to access fresh, locally grown, and/or organic food. FMs' social functions also distinguish them from traditional food sales venues. In addition, FMs help revitalize the local economy by generating local business opportunities and are an integral link between the rural and urban areas (AMS/USDA, 2011c; Hunt, 2007).

The prevalence of FMs across the United States provides opportunities for local farmers to expand their businesses in response to increasing consumer demand. Unfortunately, some vendors may take unfair advantage of

Received for publication 5 Mar. 2012. Accepted for publication 11 June 2012.

${ }^{1}$ To whom reprint requests should be addressed; e-mail zfgao@ufl.edu. consumer perception that most foods sold in FMs are locally grown, fresh, grown by farmers themselves, or organically produced (Kremen et al., 2003). Unscrupulous vendors may provide misleading or inaccurate information to sell products that do not meet consumer perception about what is being bought at FMs. In 2010, there were several instances in southern California where some FM vendors repacked wholesale produce and sold the produce as grown by themselves (Grover and Goldberg, 2010; Karp, 2010). Some of those products were imported from Mexico. In addition, some large growers were selling their products at FMs, which contradicts the perception that most FM growers are small- and midsized operations.

Most FMs have strict regulations to prevent the resale of products and will penalize vendors who mislabel or make misleading statements about their products. However, the key product characteristics (e.g., locally grown, grown by vendor, from small farm) that attract consumers to FMs are credence attributes that are not observable to most consumers (Darby and Karni, 1973; Nelson, 1970). [Product attributes can be classified as search, experience, and credence attributes. Search attributes are those that can be observed before purchase (e.g., shape, color); experience attributes are those that can only be observed after purchase (e.g., taste); and credence attributes are those that cannot be observed either before or after purchase (e.g., locally produced, organically produced).] One way to correct this situation is for FM vendors to provide information about their products (e.g., having signs stating that the products for sale are organic). However, investigating potential violations and verifying information provided by the vendors are both time-consuming and costly. For instance, in 2010, 75 famers at $30 \mathrm{FMs}$ in the Los Angeles area were found to have violated FM regulations; inspecting $\approx 700$ vendors at FMs in Los Angeles County that year cost $\$ 147,000$ for $\approx 2,050$ inspection hours (Barrett, 2011).

For FM managers and honest vendors who strictly follow the rules, one of the most important concerns is the impact of dishonest sales practices on consumer shopping behavior. Will the undesirable practices by some FM vendors turn consumers away totally from the FMs where those vendors sell? Which types of consumers are more likely to change their behavior if they find out that products sold by some vendors do not meet their expectations? Much of the research on FMs has focused on FM consumer profiles (Wolf, 1997; Wolf et al., 2005), the reasons why consumers go to FMs (Feagan and Morris, 2009), consumer demand for FMs (Alonso and O'Neill, 2010), and consumer expectations about FM products (Andreatta and Wickliffe, 2002; Trobe, 2001). Research has also been conducted to determine the nature of the interaction between FM consumers and vendors as well as the factors that affect the development of FMs (Hofmann et al., 2009; Hunt, 2007). Brown (2001) presented a detailed review of the history, definition, and classification of FMs. In addition, Brown (2002) gave a comprehensive review of FM research from 1940 to 2000 that called for more research about the social and non-economic aspects of FMs. To our knowledge, little research has investigated consumer knowledge of and response to cheating, false claims, and other dishonest sales practices at FMs. With the rapid growth of FMs, chances increase that dishonest vendors will sell at FMs to obtain an additional source of income. Consumer responses to these changes in the composition of vendors at FMs will play important roles in the future development of FMs across the United States.

This study examined consumers' perception of the characteristics of produce sold at three FMs in Florida. The characteristics of interest are credence attributes such as the freshness of the product or whether the product is locally grown. The relationship between the consumers' perception of these attributes and persistence of shopping at FMs, or loyalty to FMs, was also examined. Both customers and managers of three FMs were included in the study. This permitted the researchers to compare actual credence attributes of products sold at the FMs, as reported by the market managers, with customers' perception with regard to the same credence attributes. 


\section{Materials and Methods}

Manager and consumer surveys. The FM manager questionnaire was used to obtain basic information about the FMs regarding the number of vendors who sell locally produced, organic, and/or products grown by the vendor him- or herself. The consumer questionnaire contained the same items regarding the number of vendors who sell different types of products. Manager and consumer data were compared to measure consumer knowledge of the FMs. The consumer questionnaire also included measures of the main reasons why consumers shop at FMs, the importance of product characteristics to the consumers personally, and consumer loyalty to the FMs where they shopped. In addition, consumer demographics and personal shopping experiences at FMs were included.

In Oct. 2009, one FM in each of the three Florida areas (Gainesville, Keystone Heights, and Tampa) was visited to conduct the surveys. The markets were chosen to represent the range of populations who may shop at FMs in Florida. Gainesville's student and university-affiliated populations represent the higher educational levels typical of many FM customers nationally. Keystone Heights is a peri-urban, small town typical of many commuter communities. Tampa is a major metropolitan area with a diverse population. The FM in Gainesville has 45 vendors, the FM in Keystone Heights has approximately eight to 10 vendors, and the FM in Tampa has 55 vendors. One manager or representative at each FM was interviewed for the FM manager survey. The consumer survey was conducted by randomly stopping consumers at FMs. A $\$ 1$ incentive was given to each participant to increase the response rate. A total of 165 surveys were completed. After removing the incomplete questionnaires, 124 observations were used in the final analysis. The numbers of observations for Gainesville, Keystone Heights, and Tampa were 84, 17, and 23, respectively.

Data analyses. Logit models were used to determine the impacts of undesirable or fraudulent vendor practices on consumer loyalty. In logit models, the probability that a consumer would continue to shop at the FM was

$$
P\left(y_{i}=1\right)=\frac{e^{\beta^{\prime} \cdot X_{i}}}{1+e^{\beta^{\prime} \cdot X_{i}}},
$$

where $\beta$ was a vector of coefficients to be estimated and $X$ was a vector of variables that might affect consumer shopping behavior. The log likelihood of the ith observation was

$$
l(\beta)=y_{i} \log (P)+\left(1-y_{i}\right)[\log (1-P)] .
$$

For a sample with $N$ respondents, the $\log$ likelihood function could be written as

$$
\mathcal{L}(\beta)=\sum_{i=1}^{N} l(\beta) .
$$

Eq. (3) was maximized to obtain the estimates of $\beta$ (Wooldridge, 2010).
In addition, Eq. (1) was equivalent to

$$
\begin{aligned}
P\left(y_{i}=1\right) & =\frac{e^{\beta^{\prime} \cdot X_{i}}}{1+e^{\beta^{\prime} \cdot X_{i}}} \equiv \ln \left(\frac{P}{1-P}\right) \\
& =\beta^{\prime} \cdot X_{i} .
\end{aligned}
$$

As a result, the coefficient of $X$ could be interpreted as the marginal effect of $X$ on the $\log$ of the odds ratio that a consumer would continue or stop shopping at FMs. A positive coefficient indicated that with a one-unit increase in the independent variable, the probability that a consumer would continue to shop was higher than the probability that a consumer would stop shopping at FMs.

\section{Results}

Consumer characteristics. The average age of the 124 respondents was 36 , and median annual household income was $\$ 40,781$. More than $60 \%$ of the respondents were females and more than $40 \%$ had completed a university or higher degree. Compared with all Florida citizens (U.S. Census Bureau, 2011), the sample was younger, had a lower income, and had a higher educational level. In addition, more than $70 \%$ of respondents were white and $\approx 59 \%$ had full- or part-time jobs (Table 1). Some characteristics of the consumer profiles in the sample were similar to previous findings that consumers at FMs were more likely to be female and have higher educational levels than the population as a whole (Kezis et al., 1998; Wolf et al., 2005). The lower income and younger age in our sample were mainly attributed to the respondents from Gainesville. Gainesville is a college town, where approximately half of the residents are college students, which makes the city's median household income and median resident age significantly lower than other Florida cities.

Some $36.3 \%$ of the respondents shopped at FMs at least once a week, and 55.6\% had been shopping at FMs for more than 1 year. There were some long-term FM consumers who had been shopping at FMs for more than 6 years. Those respondents accounted for $26.6 \%$ of the sample. Some $21.0 \%$ of respondents used FMs as their main source of fruits and vegetables with more than $60 \%$ of their fruit and vegetable purchases from FMs. However, for most consumers $(41.9 \%)$, fruits and vegetables from FMs accounted for less than $20 \%$ of their total fruit and vegetable purchases. These results were not unexpected because all three FMs were only open once a week, making reliance on FMs as their major source of fruits and vegetables very inconvenient. The limited operation day of FMs has been shown to be a key reason that consumers do not shop at FMs (Govindasamy et al., 2002).

Reasons to shop at and perceptions of farmers' markets. A 5-point Likert scale was used to determine consumer perception of FMs. Consumers were asked to express their agreement with statements such as "Shopping at FMs is good for the environment" and "I enjoy the atmosphere at FMs" (Table 2). These statements covered different aspects of
Table 1. Descriptive statistics of respondents in three Florida farmers' markets.

\begin{tabular}{|c|c|}
\hline Variables & Definitions \\
\hline \multicolumn{2}{|c|}{$\begin{array}{l}\text { How strongly do you agree with the following } \\
\text { statements (agreement scale)? }\end{array}$} \\
\hline ENV & $\begin{array}{l}\text { Shopping at FM is good for the } \\
\text { environment. }\end{array}$ \\
\hline ATM & I enjoy the atmosphere at FM. \\
\hline $\mathrm{KNO}$ & $\begin{array}{l}\text { People who shop at FM are } \\
\text { knowledgeable about food. }\end{array}$ \\
\hline SUP & $\begin{array}{l}\text { It is better to shop at FM than } \\
\text { the supermarket. }\end{array}$ \\
\hline $\mathrm{SOC}$ & FM is a good place to socialize. \\
\hline FRI & I like meeting my friends at FM \\
\hline CAR & $\begin{array}{l}\text { Shopping at FM helps me } \\
\text { reduce my carbon footprint. }\end{array}$ \\
\hline
\end{tabular}

\begin{tabular}{lcc}
\hline Variable & Mean & SD \\
\hline Age & 36.2 & 15.3 \\
& Frequency & Percent \\
Gender & & \\
$\quad$ Female & 80 & $64.5 \%$ \\
Income & & \\
$\quad$ Less than $\$ 30,000$ & 55 & $44.4 \%$ \\
$\quad \$ 30,000$ to $\$ 49,999$ & 28 & $22.6 \%$ \\
$\quad$ \$50,000 to $\$ 74,999$ & 24 & $19.4 \%$ \\
$\quad$ \$75,000 or more & 17 & $13.7 \%$ \\
Education & & \\
$\quad$ High school or lower & 14 & $11.3 \%$ \\
Postsecondary & 58 & $46.8 \%$ \\
$\quad$ technical school & & \\
$\quad$ or college & & \\
Completed university & 25 & $20.2 \%$ \\
$\quad$ undergraduate degree & & \\
$\quad$ Postgraduate degree & 27 & $21.8 \%$ \\
Ethnic & & \\
$\quad$ White/Caucasian & 88 & $71.0 \%$ \\
$\quad$ Black/African American & 9 & $7.3 \%$ \\
Asian & 11 & $8.9 \%$ \\
Hispanic/Latino & 11 & $8.9 \%$ \\
$\quad$ Other & 5 & $4.0 \%$ \\
Employment & & \\
$\quad$ Currently employed & 73 & $58.9 \%$ \\
Homemaker & 4 & $3.2 \%$ \\
$\quad$ Student & 28 & $22.6 \%$ \\
Retired & 9 & $7.3 \%$ \\
Currently unemployed & 11 & $8.1 \%$ \\
\hline
\end{tabular}

Table 2. Names of variables assigned to principle reasons given by consumers for shopping at farmers' markets.

How important are following factors in your decision to shop at FM (importance scale)? FRESH Freshness of produce

LOCAL Food is locally produced

ORGANIC Availability of organic produce GROWER Know who grows my food

Agreement scale: $1=$ strongly disagree, $2=$ disagree, $3=$ neutral, $4=$ agree, $5=$ strongly agree; importance scale: $1=$ not at all important, $2=$ not important, $3=$ neutral, $4=$ important, $5=$ very important.

$\mathrm{FM}=$ farmers' market.

the "embeddedness" that motivated consumers to shop at FMs such as social embeddedness, spatial embeddedness, and natural embeddedness (Feagan and Morris, 2009). Social embeddedness refers to consumer demand for interactions with people such as meeting friends or family members. Spatial embeddedness refers to the desire to have more direct links with the food being purchased such as purchasing local food. Natural embeddedness 
refers to motivations to protect nature and support more sustainable lifestyles (Feagan and Morris, 2009). Figure 1 shows that $\approx 94 \%$ of respondents thought that FMs had a desirable atmosphere and $\approx 90 \%$ agreed that shopping at FMs helped protect the environment. FMs as a place for socializing was the third most important factor with more than $83 \%$ agreeing that FMs were a good place for socializing. At more than $67 \%$, the statements such as "I like to meet friends at FMs" and "People who shop at FMs are knowledgeable about food" were the least agreed in the survey (Fig. 1). These results indicated that, other than the space for buyer and seller to make money-product exchanges, the social amenities provided by FMs could be more important to some consumers.

The ability of FMs to provide fresh and locally produced food was shown to be the most important reason for consumers shopping at FMs. Some $98.4 \%$ and $93.6 \%$ of respondents rated food freshness and local food, respectively, as the most important factors in their decision to shop at FMs. Availability of organic food and knowing the persons growing the food were rated important by $78.2 \%$ and $80.7 \%$ of respondents, respectively (Fig. 2).

Perceptions and knowledge of famers' market vendors. Respondents were asked about their perception of the freshness of products sold at FMs, their definition of local products, and their estimates of the percentage of the vendors selling different types of products. Most consumers thought that the produce sold at FMs had been harvested $\approx 2$ to $3 \mathrm{~d}$ before sales $(57.3 \%)$. Some $29 \%$ and $13.7 \%$ of respondents thought the produce had been harvested less than $1 \mathrm{~d}$ and more than $3 \mathrm{~d}$, respectively (Table 3 ). Although a popular concept in the United States, there is no clear definition of local food. The majority of respondents in our sample considered food produced within 50 miles as local $(46.7 \%)$. The percentage of respondents who considered food produced within 100 miles, 200 miles, and in Florida as local were $25.8 \%$, $8.9 \%$, and $17.7 \%$, respectively. There were a few people who thought food produced in the United States could be defined as local food (Table 3).

Only $15.3 \%$ of respondents thought that more than $80 \%$ of the vendors at the FMs sold local food. Approximately 36.3\%, 29.8\%, and $17.7 \%$ of respondents thought that the percentages of vendors who sold local food were $61 \%$ to $80 \%, 41 \%$ to $60 \%$, and $21 \%$ to $40 \%$, respectively. There were a few respondents who believed less than $20 \%$ of the vendors sold local products. Compared with estimates of the number of vendors selling local products, estimates of the number of organic growers were relatively low. Only $2.4 \%$ of the respondents believed that more

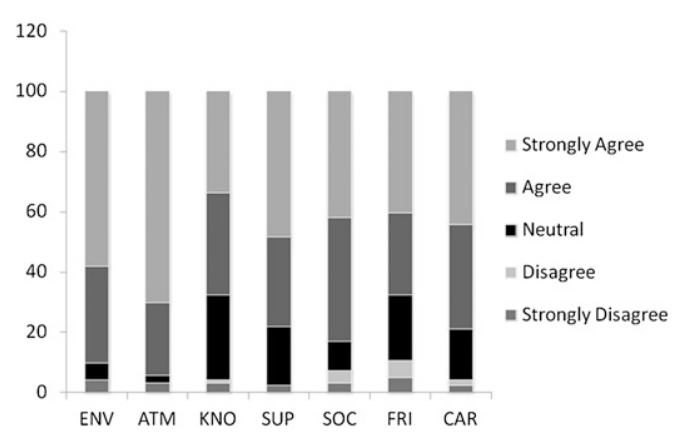

Fig. 1. Frequency of scalar responses of consumers at three farmers' markets in Florida to statements representing seven primary reasons for shopping at farmers' markets. ENV = shopping at FM is good for the environment; $\mathrm{ATM}=\mathrm{I}$ enjoy the atmosphere at $\mathrm{FM}$; $\mathrm{KNO}=$ people who shop at FM are knowledgeable about food; SUP $=$ it is better to shop at FM than the supermarket; SOC $=\mathrm{FM}$ is a good place to socialize; FRI = I like meeting my friends at FM; CAR = shopping at FM helps me reduce my carbon footprint. $\mathrm{FM}=$ farmers' market.

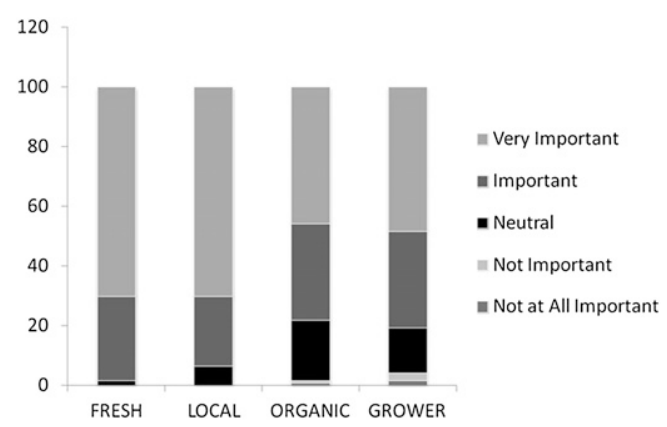

Fig. 2. Frequency of scalar responses of consumers at three farmers' markets in Florida to four factors that affect consumers' decision to shop at farmers' markets. FRESH $=$ freshness of produce; LOCAL = food is locally produced; ORGANIC $=$ availability of organic produce; GROWER $=$ know who grows my food.

than $80 \%$ of the vendors sold organic products, whereas more than $24 \%$ of the respondents thought that the number of vendors selling organic products was less than $20 \%$ of the total vendors at FMs. Most respondents estimated that the number of vendors selling organic products was $\approx 21 \%$ to $40 \%$ (Table 3 ). Some $13.7 \%$ of the respondents believed that the number of vendors selling self-grown products was $81 \%$ to $100 \%$. Many respondents $(33.9 \%)$ estimated that the number of vendors selling products that they grew or made themselves was between $41 \%$ to $60 \%$ (Table 3). Comparing the respondents' estimates of vendors selling local and organic products, FMs were more likely to be considered by consumers as places to purchase locally produced products rather than organic products or products grown by the vendors themselves.

FM managers' estimates of the harvest time and definition of local products differed across the three FMs. Managers of the FMs at Gainesville and Keystone Heights estimated that the produce sold at the FMs were harvested within $1 \mathrm{~d}$, and the manager of the Tampa FM estimated that most of the produce were harvested in the past 2 or $3 \mathrm{~d}$. Both managers at the Gainesville and Tampa FMs thought local products could be defined as products produced in Florida, whereas managers at the Keystone Heights FM believed local products should be produced within 100 miles. FM managers at Gainesville, Keystone Heights, and Tampa estimated that the numbers of vendors selling local products were $61 \%$ to $80 \%, 81 \%$ to $100 \%$, and $41 \%$ to $60 \%$, respectively. Because there were only eight to 10 vendors at the Keystone Heights FM, the manager was confident that most of the products at the FM were produced locally. The estimated numbers of vendors selling organic products were very low at all three FMs. The manager at the Gainesville FM thought that $\approx 21 \%$ to $40 \%$ vendors sold organic food, whereas the managers at the Keystone Heights and Tampa FMs believed that less than $20 \%$ of the vendors sold organic products. FM managers at Gainesville, Keystone Heights, and Tampa thought the numbers of vendors who sold products grown by the vendors themselves were $81 \%$ to $100 \%, 61 \%$ to $80 \%$, and $21 \%$ to $40 \%$, respectively.

Consumers' perception of harvest time of fresh produce at the FMs, definition of local products, and estimates of vendors selling different types of products were compared with perceptions of the corresponding FM managers. Table 4 reports the frequency of differences in the Likert scale between the answers of consumers and the corresponding FM managers to the same questions. If a consumer and manager had the same estimates, the number in Table 4 would be zero. The larger the absolute numbers in Table 4, the less knowledge the consumers had about the FMs. Results in Table 4 showed that $35.5 \%$ of the consumers had the same estimates as the managers regarding the harvest time of produce sold at FMs and that $61.3 \%$ of the consumers overestimated the time 
Table 3. Consumers' perception of selected characteristics of food products sold at three farmers' markets in Florida.

\begin{tabular}{lrc}
\hline Variables & Frequency & Percent \\
\hline Definition of local (DLOCAL) & & \\
Produced within 50 miles & 57 & $46.0 \%$ \\
Produced within 100 miles & 32 & $25.8 \%$ \\
Produced within 200 miles & 11 & $8.9 \%$ \\
Produced within Florida & 22 & $17.7 \%$ \\
Produced within & 2 & $1.6 \%$ \\
$\quad$ the United States & & \\
Harvest time (HARTIME) & & \\
1 d or less & 36 & $29.0 \%$ \\
2 or 3 d & 71 & $57.3 \%$ \\
More than 3 d & 17 & $13.7 \%$ \\
Local products (PLOCAL) & & \\
$0 \%$ to $20 \%$ & 1 & $0.8 \%$ \\
$21 \%$ to $40 \%$ & 22 & $17.7 \%$ \\
$41 \%$ to $60 \%$ & 37 & $29.8 \%$ \\
$61 \%$ to $80 \%$ & 45 & $36.3 \%$ \\
$81 \%$ to $100 \%$ & 19 & $15.3 \%$ \\
Organic products (PORG) & & \\
$0 \%$ to $20 \%$ & 30 & $24.2 \%$ \\
$21 \%$ to $40 \%$ & 41 & $33.1 \%$ \\
$41 \%$ to $60 \%$ & 31 & $25.0 \%$ \\
$61 \%$ to $80 \%$ & 19 & $15.3 \%$ \\
$81 \%$ to $100 \%$ & 3 & $2.4 \%$ \\
Sell-grown products (PGRO) & & \\
$0 \%$ to $20 \%$ & 16 & $12.9 \%$ \\
$21 \%$ to $40 \%$ & 20 & $16.1 \%$ \\
$41 \%$ to $60 \%$ & 32 & $33.9 \%$ \\
$61 \%$ to $80 \%$ & $23.4 \%$ \\
$81 \%$ to $100 \%$ & $13.7 \%$ \\
\hline
\end{tabular}

from harvest to sale. Only $17.7 \%$ of the consumers shared the same view as the FM managers regarding the definition of local products and $77.4 \%$ of the consumers' definitions were stricter than those of the managers. Consumers' definition of local products required that they be produced within fewer miles than that of the FM managers. Approximately $31.5 \%$ of consumers' estimates of the number of vendors selling local products were the same as those of the FM managers (Table 4). However, the actual level of agreement was lower because consumers demanded local products to be produced in closer proximity to the market than did the FM managers. Some $36.3 \%$ of consumers had similar estimates of the number of vendors selling certified organic products in comparison with the estimates from managers, whereas $\approx 52.4 \%$ of consumers overestimated the number of vendors selling organic products. Only $17.7 \%$ of the consumers reached the same estimates as did the FM managers regarding the number of vendors selling self-grown products with most consumers underestimating the number of vendors who sold self-grown products (Table 4).

Loyalty of farmers' market consumers. Consumers were asked whether they would stop shopping at the FM if found out that the products they purchased did not meet their expectations. Four scenarios were described in the questionnaire: 1) the produce have been harvested for a period longer than consumer thought; 2) the produce are not produced locally based on consumers' definition of a local product; 3 ) the produce are not organic; or 4 ) the products are not grown or made by
Table 4. Concurrence between consumers' perceptions and FM managers' reports of selected characteristics of products sold at three farmers' markets in Florida.

\begin{tabular}{lcc}
\hline Variables & Frequency & Percent \\
\hline Definition of local & & \\
Consumers have & 48 & $38.7 \%$ \\
-3 (much stricter definition of local food than FM managers) & 29 & $23.4 \%$ \\
-2 (stricter definition of local food than FM managers) & 19 & $15.3 \%$ \\
-1 (some stricter definition of local food than FM managers) & 22 & $17.7 \%$ \\
0 (the same definition of local food as FM managers) & 2 & $1.6 \%$ \\
1 (some less strict definition of local food than FM manager) & 3 & $2.4 \%$ \\
2 (less strict definition of local food than FM manager) & 1 & $0.8 \%$ \\
3 (much less strict definition of local food than FM manager) & & \\
Harvest time (time from harvest to market) & 4 & $3.2 \%$ \\
Consumers' estimates of harvest time of produce is & 44 & $35.5 \%$ \\
-1 (shorter than that of FM managers') & 66 & $53.2 \%$ \\
0 (the same as that of FM managers') & 10 & $8.1 \%$ \\
1 (some longer than that of FM managers') & & \\
2 (longer than that of FM managers') & 3 & $2.4 \%$ \\
Local products & 15 & $12.1 \%$ \\
Consumers' estimates of vendors selling organic products is & 45 & $36.3 \%$ \\
-3 (much smaller than FM managers') & 39 & $31.5 \%$ \\
-2 (smaller than FM managers') & 19 & $15.3 \%$ \\
-1 (some smaller than FM managers') & 3 & $2.4 \%$ \\
0 (the same as FM managers') & & \\
1 (some larger than FM managers') & & \\
2 (larger than FM managers') & &
\end{tabular}

Organic products

Consumers' estimates of vendors selling organic products is

-1 (some smaller than FM managers')

0 (the same as FM managers')

1 (some larger than FM managers')

2 (larger than FM managers')

3 (much larger than FM managers')

Self-grown products

Consumers' estimates of vendors selling self-grown products is

-4 (very much smaller than FM managers')

-3 (much smaller than FM managers')

-2 (smaller than FM managers')

-1 (some smaller than FM managers')

0 (the same as FM managers')

1 (some larger than FM managers')

2 (larger than FM managers')

3 (much larger than FM managers')

FM $=$ farmers' market.

$36.3 \%$

$31.5 \%$

$2.4 \%$

$\begin{array}{rr}14 & 11.3 \% \\ 45 & 36.3 \% \\ 37 & 29.8 \% \\ 19 & 15.3 \% \\ 9 & 7.3 \%\end{array}$

\begin{tabular}{rr}
4 & $3.2 \%$ \\
17 & $13.7 \%$ \\
37 & $29.8 \%$ \\
31 & $25.0 \%$ \\
22 & $17.7 \%$ \\
7 & $5.7 \%$ \\
4 & $3.2 \%$ \\
2 & $1.6 \%$ \\
\hline
\end{tabular}

the vendors themselves. The numbers of respondents who would continue shopping at the FMs were $75.8 \%$ for longer harvest time, $53.2 \%$ for products not being local products, $66.1 \%$ for products not being organic products, and $62.1 \%$ for products not grown by the vendor (Table 5). These results indicated that the undesirable sale practices of vendors did not have strong negative impacts on most consumers' shopping at the FMs. However, the vendors' practices would turn away consumers who would then purchase products from other vendors at the FMs. The results indicated that longer harvest time had the least impact on consumer loyalty to shopping at the FMs, whereas not being local products had the greatest impact. It may be that consumers believed they could more easily estimate the harvest time of produce by checking the freshness of the products than verify whether the products were produced locally.

Four logit models were estimated in SAS 9.2 (SAS Institute, Inc., Cary, NC) to determine the strength of factors that affected consumer loyalty to shopping at FMs. The dependent variables indicated whether a consumer would continue to shop at the FMs in four different scenarios. The independent variwould continue to shop at three farmers' markets in Florida if they learned that their perceptions of selected characteristics of products sold at the markets were different from the actual characteristics of those products.

\begin{tabular}{lcc}
\hline Product characteristics & Frequency & Percentage \\
\hline Longer harvest time & 94 & $75.8 \%$ \\
Not local products & 66 & $53.2 \%$ \\
Not organic products & 82 & $66.1 \%$ \\
Not grown by the vendor & 77 & $62.1 \%$
\end{tabular}

ables could include many factors such as demographics, shopping behaviors, attitudes, and perceptions that might affect consumer loyalty. However, our results showed that demographics, shopping behaviors, and perceptions and knowledge of vendors did not have significant impacts on consumer loyalty. Based on Akaike information criterion (AIC), only the reasons for shopping at FMs and the FM locations are included in the final regression models.

The models were specified as $\left(y_{i}=1\right)=$ $\frac{e^{\beta^{\prime} \cdot X_{i}}}{1+e^{\beta^{\prime} \cdot X_{i}}}$, where X $=($ FM1, FM3, ENV, ATM, KNO, SUP, SOC, FRI, CAR, FRESH, LOCAL, ORGANIC, GROWER). FM1 and FM3 were
Table 5. Number and percentage of consumers who 
Table 6. Logit models determining the strength of factors on consumer loyalty to farmers' markets.

\begin{tabular}{|c|c|c|c|c|c|c|c|c|}
\hline \multirow[b]{2}{*}{ Variables } & \multicolumn{2}{|c|}{ Longer harvest time } & \multicolumn{2}{|c|}{ Not local products } & \multicolumn{2}{|c|}{ Not organic products } & \multicolumn{2}{|c|}{ Not grown by the vendor } \\
\hline & Estimates & SD & Estimates & SD & Estimates & SD & Estimates & SD \\
\hline$\overline{\text { FM1 }}$ & -1.13 & 0.87 & $-1.57 * *$ & 0.74 & $-2.23 * *$ & 0.98 & $-1.65 * *$ & 0.82 \\
\hline FM3 & $-1.66^{*}$ & 0.97 & -1.10 & 0.88 & $-1.80 *$ & 1.09 & -0.83 & 0.96 \\
\hline ENV & -0.45 & 0.45 & -0.33 & 0.44 & 0.29 & 0.41 & 0.21 & 0.44 \\
\hline ATM & -0.25 & 0.50 & $0.94 * *$ & 0.50 & 0.48 & 0.48 & 0.39 & 0.48 \\
\hline KNO & 0.41 & 0.35 & -0.23 & 0.34 & -0.23 & 0.32 & -0.16 & 0.35 \\
\hline SUP & 0.52 & 0.37 & $-0.91 * *$ & 0.40 & -0.42 & 0.36 & $-0.66^{*}$ & 0.39 \\
\hline SOC & $0.74 * *$ & 0.39 & $0.88 * *$ & 0.41 & 0.18 & 0.39 & $0.97 * *$ & 0.44 \\
\hline FRI & -0.56 & 0.34 & $-0.76 * *$ & 0.34 & 0.06 & 0.31 & -0.23 & 0.32 \\
\hline CAR & 0.16 & 0.34 & $0.77 * *$ & 0.37 & -0.08 & 0.33 & -0.09 & 0.37 \\
\hline FRESH & -0.15 & 0.49 & 0.03 & 0.44 & -0.63 & 0.49 & 0.27 & 0.46 \\
\hline LOCAL & 0.04 & 0.48 & $-0.87 * *$ & 0.47 & -0.12 & 0.46 & $-0.89 *$ & 0.53 \\
\hline ORGANIC & $-0.92 * *$ & 0.44 & 0.18 & 0.37 & $-0.78 * *$ & 0.41 & $-0.71 *$ & 0.41 \\
\hline GROWER & 0.08 & 0.35 & -0.52 & 0.33 & 0.43 & 0.34 & 0.19 & 0.35 \\
\hline Intercept & 4.20 & 2.89 & $4.89 * *$ & 2.67 & $6.27 * *$ & 2.95 & $4.95^{*}$ & 2.96 \\
\hline$-\log L$ & \multicolumn{2}{|c|}{90.53} & \multicolumn{2}{|c|}{139.12} & \multicolumn{2}{|c|}{99.89} & \multicolumn{2}{|c|}{135.18} \\
\hline
\end{tabular}

FM1 = Gainesville farmers' market; FM3 = Tampa farmers' market; ENV = shopping at FM is good for the environment; ATM = I enjoy the atmosphere at FM; $\mathrm{KNO}=$ people who shop at FM are knowledgeable about food; $\mathrm{SUP}=$ it is better to shop at FM than the supermarket; $\mathrm{SOC}=\mathrm{FM}$ is a good place to socialize; FRI = I like meeting my friends at FM; CAR = shopping at FM helps me reduce my carbon footprint; FRESH = freshness of produce; LOCAL = food is locally produced; ORGANIC = availability of organic produce; GROWER = know who grows my food; FM = farmers' market.

$*$ and ** indicate $10 \%$ and $5 \%$ significance levels, respectively.

dummy variables indicating whether a respondent was from Gainesville or Tampa (FM2 for Keystone Heights was chosen as the benchmark category). The other variables were defined in Table 2. The logit model analyses (Table 6) indicated that the variables had different impacts on consumer loyalty. For instance, many variables showed significant impacts on consumer loyalty if they learned that the produce they purchased were not local, but few variables exhibited significant impacts on consumer loyalty if they learned that the produce were harvested earlier than they expected. If a variable had significant impacts on consumer loyalty, the impacts were in the same direction for the four models. For instance, SOC had positive impacts on consumer loyalty in Models 1, 2, and 4, but not in Model 3. It indicated that consumers who thought FMs were a good place to socialize are more likely to continue to shop at the FM, no matter whether the produce they purchased were harvested earlier than thought, not local, or not grown by the vendors. Consumers who enjoyed the atmosphere at FMs were more likely to continue shopping there even if produce were not locally produced. However, consumers who thought shopping at FMs was better than at the supermarket and those who thought local food was very important were more likely to stop shopping at the FM if they found out the products they purchased were not locally produced. In addition, consumers who considered the availability of organic produce as one of the important reasons to shop at FMs were more likely to stop shopping at the FM if they found out the products they purchased were not organic. Furthermore, if all other variables were the same, consumers at the Gainesville and Tampa FMs were more likely to stop shopping at the FM than were consumers at the Keystone Heights FM. This may be because the Keystone Heights FM had very few vendors, including many vendors who did not sell fruits and vegetables. Hence, the main purpose for consumer visits to the
FM might involve activities other than shopping for fruits and vegetables.

\section{Discussion}

The rapid growth of FMs may change the nature of FMs, thereby reducing the ways in which consumers perceive FMs as different from other food-purchasing venues. Understanding consumers' perceptions and knowledge of FMs and their loyalty to FMs may provide useful information for developing guidelines for FM managers and other stakeholders to ensure the continued expansion of FMs in the future.

Our results show that the social amenities provided by FMs may be more important than FMs' function as a place for moneyproduct exchanges. Consumers enjoy the atmosphere at the FMs and use them as a place for socializing. Shopping at the FMs is also seen as a way to protect the environment and reduce one's carbon footprint. The produce being local and fresh are possibly the two most important characteristics for FM consumers. However, FMs as good places to purchase organic and farmer self-grown products are also key factors for consumers. These results are consistent with previous studies that demonstrate the importance of the multifunctionality of FMs and the idea that consumers who shop at FMs are seeking values beyond the foods themselves (AMS/ USDA, 2011c; Feagan and Morris, 2009; Hunt, 2007). Using FM managers' estimates as benchmarks, the results show that consumers have limited knowledge of the FM where they shop. Many consumers overestimated the time from harvest to sale and underestimated the number of vendors selling local and self-grown products. Because freshness of produce and the availability of local food are the two key factors affecting consumer purchase of food products (Govindasamy et al., 2002), FM managers and vendors can emphasize the short harvest-to-sale time and the availability of local and self-grown products at FMs to attract more consumers. Furthermore, if FM managers want to expand their customer base, they may focus on building a market of mainly local vendors and establishing harvest-to-sale time requirements.

In most cases, FM consumers appear very loyal to the market where they shop. More than half of the consumers surveyed indicated that they would continue to shop at the FMs even if the product they purchased turned out to be different from what they expected. In addition, consumers who care more about the shopping environment are more loyal that those who emphasize local, organic food and the superiority of shopping at FMs. This implies that, in addition to focusing on the quality of products, FM managers may consider providing better social amenities to create a desirable shopping environment. Consumers who are attracted by the shopping atmosphere can be a stable customer base. This is because the FM "is more than just a physical space for commercial transactions"; the market is "an active contributor to the cultural dynamic within which those transactions take place" (Andreatta and Wickliffe, 2002, p. 1). In addition, FM managers should be clear about their philosophy of the FMs and have a better knowledge of the types of vendors at their FMs. This will help them deliver more accurate information to consumers so as to reduce the gap between consumer expectation and reality. FM managers may also consider using source verification to reduce the asymmetric information problem between vendors and consumers. This will improve the development of the market and in the long run increase the reputation of the FMs. However, this action may require large amounts of time and money. FM managers should decide to what degree source verification should be implemented based on their own unique situations (e.g., benefit, cost, etc.).

The present study only included three Florida FMs. Further studies could generate a larger sample size and include a wider variety of markets in other Florida counties 
or in other states. In addition, in this study, consumer knowledge of the FMs was measured based on the difference between consumer and FM manager estimates of the numbers of vendors selling different types of products. More accurate measures of consumer knowledge could be created if FM vendors provide accurate information about their practices. This research is a stepping stone for FM managers, customers, and others interested in sustaining the growth of FMs.

\section{Literature Cited}

Alonso, A.D. and M.A. O'Neill. 2010. A comparative study of farmers' markets visitors' needs and wants: The case of Alabama. Intl. J. Consum. Stud. 35:290-299.

AMS/USDA. 2011a. Farmers market growth. Farmers markets and local food marketing. U.S. Department of Agriculture, Washington, DC. <http://www.ams.usda.gov/AMSv1.0/ams. fetchTemplateData.do?template $=$ TemplateS\& leftNav $=$ WholesaleandFarmersMarkets \& page $=$ WFMFarmersMarketGrowth\&description= Farmers\%20Market\%20Growth\&acct= frmrdirmkt>.

AMS/USDA. 2011b. Farmers' markets and local food marketing. U.S. Department of Agriculture, Washington, DC. $<$ http://www.ams.usda.gov/ AMSv1.0/ams.fetchTemplateData.do?template $=$ TemplateA\&navID=WholesaleandFarmers Markets\&page $=$ WholesaleAndFarmersMarkets\& result Type $=\&$ topNav $=\&$ leftNav $=$ Wholesaleand FarmersMarkets\&acet $=$ whlsldirmkt $>$.

AMS/USDA. 2011c. Farmers market services. Farmers markets and local food marketing. U.S. Department of Agriculture, Washington,
DC. <http://www.ams.usda.gov/AMSv1.0/ getfile?dDocName=STELPRDC5080175\&acct= frmrdirmkt>.

Andreatta, S. and W. Wickliffe. 2002. Managing farmer and consumer expectations: A study of a North Carolina farmers market. Hum. Organ. 61:167-176.

Barrett, B. 2011. L.A. farmers markets exposedOften, produce sold at stalls isn't organic, grown by small farms - Or even spray-free. LA Weekly-News. LA Weekly, Culver City, CA. $<$ http://www.laweekly.com/2011-11-10/news/ 1-a-farmers-markets-exposed/4/>.

Brown, A. 2001. Counting farmers markets. Geogr. Rev. 91:655-674.

Brown, A. 2002. Farmers' market research 1940 2000: An inventory and review. Amer. J. Altern. Agr. 17:167-176.

Darby, M.R. and E. Karni. 1973. Free competition and the optimal amount of fraud. J. Law Econ. 16:67-88.

Feagan, R.B. and D. Morris. 2009. Consumer quest for embeddedness: A case study of the Brantford farmers' market. Intl. J. Consum. Stud 33:235-243.

Govindasamy, R., J. Italia, and A. Adelaja. 2002. Farmers markets: Consumer trends, preferences, and characteristics. Journal of Extension 40(1). $<$ http://www.joe.org/joe/2002february/rb6.php $>$.

Grover, J. and M. Goldberg. 2010. False claims, lies caught on tape at farmers markets-An NBCLA investigation exposes vendors at multiple farmers markets. NBC Southern California. NBC Universal, Inc. <http://www.nbclosangeles. com/news/local/Hidden-Camera-InvestigationFarmers-Markets-103577594.html>.

Hofmann, C., J.H. Dennis, and M. Marshall. 2009. Factors influencing the growth of farmers' markets in Indiana. HortScience 44:712-716.
Hunt, A.R. 2007. Consumer interactions and influences on farmers' market vendors. Renewable Agriculture and Food Systems 22:54-66.

Karp, D. 2010. Cheating scandal rocks farmers market: Was Mexican produce passed off as locally grown? Los Angeles Times, Los Angeles, CA. <http://latimesblogs.latimes.com/ lanow/2010/11/cheating-scandal-rocks-farmersmarket-was-mexican-produce-passed-off-aslocally-grown.html>.

Kezis, A., T. Gwebu, S. Peavey, and H.T. Cheng. 1998. A study of consumers at a small farmers' market in Maine: Results from a 1995 survey. Journal of Food Distribution Research 29:91-99.

Kremen, A., C. Greene, and J. Hanson. 2003. Organic produce, price premiums, and ecolabeling in US farmers' markets. Electronic report from the Economic Research Service, USDA. Retrieved January 17:2005-2005.

Nelson, P. 1970. Information and consumer behavior. J. Polit. Econ. 78:311-329.

Trobe, H.L. 2001. Farmers' markets: Consuming local rural produce. Intl. J. Consum. Stud. 25:181-192.

U.S. Census Bureau. 2011. Demographic information of Florida residence. <http://quickfacts census.gov/qfd/states/12000.html>

Wolf, M.M., A. Spittler, and J. Ahern. 2005. A profile of farmers' market consumers and the perceived advantages of produce sold at farmers' markets. Journal of Food Distribution Research 36:192-201.

Wolf, M.M.G. 1997. A target consumer profile and positioning for promotion of the direct marketing of fresh produce: A case study. Journal of Food Distribution Research 28:11-17.

Wooldridge, J.M. 2010. Econometric analysis of cross section and panel data. The MIT Press, Cambridge, MA. 